\title{
Fetal and neonatal MRI features of $A R X$-related lissencephaly presenting with neonatal refractory seizure disorder
}

\author{
Sara ffrench-Constant ${ }^{1}$, Carolina Kachramanoglou ${ }^{1}$, Brynmor Jones ${ }^{1}$, Nigel Basheer ${ }^{2}$, Nikolaos Syrmos ${ }^{3}$, \\ Mario Ganau ${ }^{4}$, Wajanat Jan ${ }^{1}$ \\ ${ }^{1}$ Department of Imaging, ${ }^{2}$ Department of Paediatrics, Imperial College Healthcare NHS Trust, London, UK; ${ }^{3}$ School of Medicine, Aristotle \\ University of Thessaloniki, Macedonia, Greece; ${ }^{4}$ Department of Neurosurgery, Oxford University Hospitals NHS Foundation Trust, Oxford, UK \\ Correspondence to: Dr. Wajanat Jan, FRCR. Department of Imaging, Imperial College Healthcare NHS Trust, London, UK. Email: w.jan@nhs.net.
}

Submitted Oct 03, 2019. Accepted for publication Oct 10, 2019.

doi: 10.21037/qims.2019.10.14

View this article at: http://dx.doi.org/10.21037/qims.2019.10.14

\section{Introduction}

Classification systems for congenital brain malformations are usually based on the stage of brain development when these abnormalities occur, hence we commonly recognize malformations as the result of disorders of cell proliferation, neuronal migration and cortical organization (1). The most modern approaches to brain malformations are based on the identification of predictive biomarkers and specific genetic profiles meant to predict their clinical presentation and functional outcome (2). For instance, lissencephaly, a subtype of this heterogeneous group of disorders, is characterized by the absence of normal convolutions of the cerebral cortex and an abnormally small head; and numerous lissencephaly-related genes are currently known to cause it (3). Nonetheless, genetic confirmation of brain malformations can prove extremely time-costly and expensive hence clinicians and radiologists are constantly attempting to define precise fetal and neonatal imaging patterns which could potentially correlate specific phenotypes with their genetic mutations (4-9). To support the rationale for this approach, we present a case where the genetic profile of a lissencephaly caused by a mutation in the aristaless-related homeobox $(A R X)$ gene was predicted solely by the precise identification of key features on prenatal and neonatal MRI. The $A R X$ gene provides instructions for producing a protein that regulates the activity of other genes, it basically encodes a transcription factor involved in neuronal migration during the early stages of brain, testes, and muscle development. The specific aim of this pictorial case presentation is to demonstrate that state of the art imaging modalities allowed identification of the clues for $A R X$ mutation during standard prenatal screening. Hence, setting the trend of ultra-early diagnosis may represent a relevant breakthrough in fetal and neonatal neuroimaging.

\section{Exemplificative case}

A couple of non-consanguineous parents, with no significant family history and two healthy children attended a routine appointment for antenatal US scan at 20 weeks of their third pregnancy. The mother (G3P2A0) was 27-years-old, and she reported that her pregnancy had been otherwise uneventful till that stage. The US unfortunately demonstrated an absent cavum septum pellucidum and suspected callosal agenesis. Given these concerning findings, another US scan was repeated at 25 weeks of gestation: this demonstrated abnormal sulcal pattern with thickened gyri in the temporoparietal regions. Of note, it was not possible to assess fetal gender in either scan. The couple was counselled to proceed with fetal MRI, which was performed at 26 weeks and confirmed the US findings but also demonstrating absence of the central sulcus and other primary sulci, in keeping with an imaging pattern of lissencephaly. There was relative prominent gyral folding of the medial temporal lobes. The neuronal eminence appeared to have remained as a mass of cells above the basal ganglia (see Figure 1). The parents were counselled but were committed to the pregnancy.

During the third trimester the mother reported abnormal fetal movements suggestive of seizure activity, and this raised the suspicions for difficult delivery by the team of 

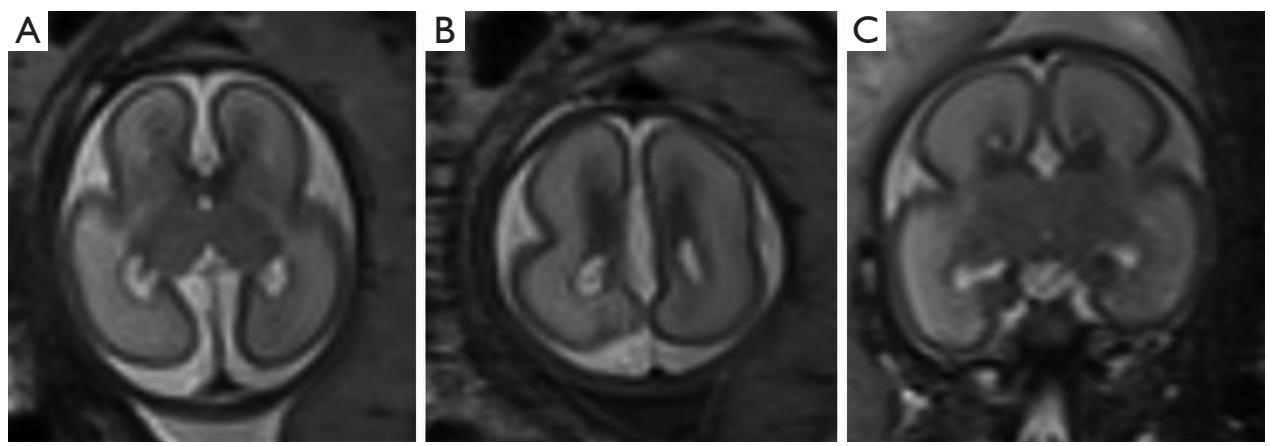

Figure 1 Fetal MRI at week 26 of gestation in the axial (A and B) and coronal planes (C) showing absent midline structures, poor sulcation and small ganglionic eminence.
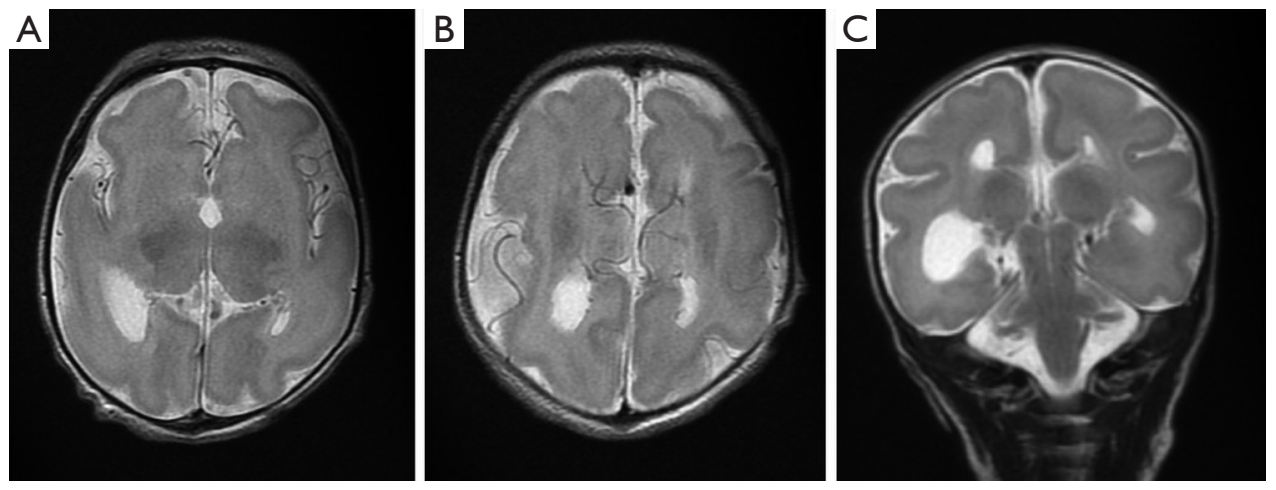

Figure 2 Neonatal MRI on day 4 of life in the axial (A and B) and coronal (C) planes showing small basal ganglia and lissencephaly with only relative thickening of the cortex. The imaging request form did not state the baby's gender.

obstetricians involved. The baby was born at 38 weeks and 3 days by vaginal delivery weighing $2.96 \mathrm{~kg}$, with normal APGAR scores at time of birth and normal blood gases. Initial neonatal assessment confirmed tone abnormalities and ambiguous genitalia. Within the first few minutes of life, baby developed seizures and cerebral function monitoring (CFM) demonstrated persistent electrical seizure activity, refractory to multi-pharmacological management with antiepileptic medications (phenobarbitone and phenytoin in addition to levetiracetam).

Neonatal MRI performed on day 4 of life (see Figure 2) demonstrated microlissencephaly with agenesis of the corpus callosum and small indistinct basal ganglia but normal brainstem and cerebellum. Findings, in combination with the lack of patient's gender on the imaging request form, were consistent with X-linked lissencephaly with ambiguous genetalia (XLAG) in keeping with $A R X$ mutation. Genetic testing indicated that the baby was a male, hemizygous for the $A R X c .994 C>A$ p mutation.

\section{Discussion}

In the past, congenital brain malformations were speculated to be relatively homogeneous clinical conditions, but as genetic, epigenetic and molecular research has progressed, the remarkable heterogeneity of these disorders has started to emerge. It is undeniable that the identification of specific causative genes, and subsequent studies shedding light on the pathophysiology cascade leading to specific phenotypes, has also led to giant leaps in the overall understanding of the development of the human brain. As for lissencephaly, multiple genetic mutations have been demonstrated and research in this field resulted in the identification of the so-called LIS-associated genes (10). The continuous advancement in the field of molecular genetics in the last decade has led to identification of at least $19 L I S$-associated genes thus far (see Table 1), many of which are related to microtubule structural proteins (tubulin) or microtubuleassociated proteins (MAPs) (4). These LIS-related 
Table 1 Comprehensive list of LIS-associated genes (information extracted from Genetic Home Reference Database, United States National Library of Medicine https://ghr.nlm.nih.gov)

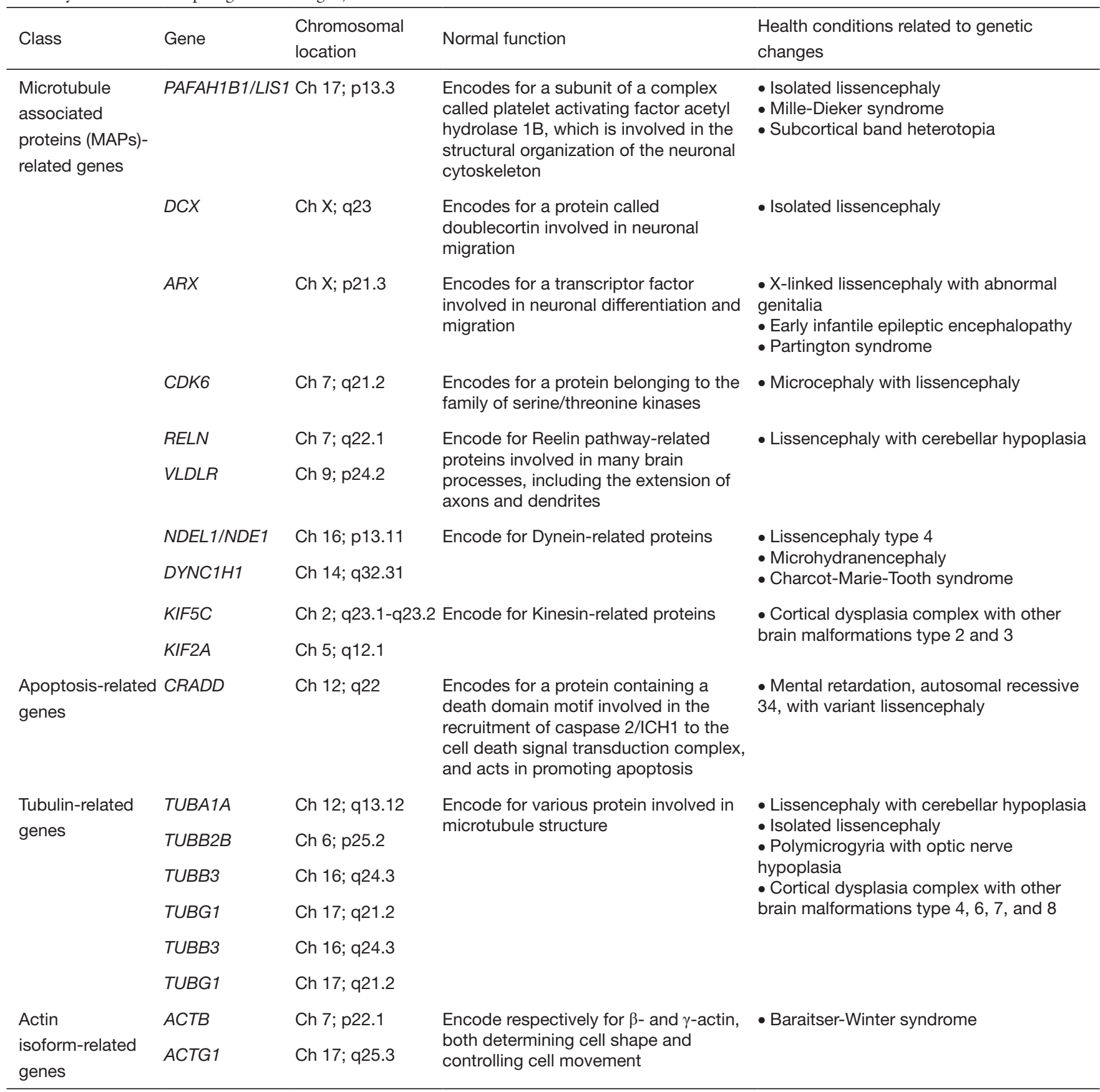

genes include LIS1, DCX, ACTB, ACTG1, ARX, CDK5, CRADD, DYNC1H1, KIF2A, KIF 5C, NDE1/NDEL1, TUBA1A, TUBA8, TUBB, TUBB2B, TUBB3, TUBG1, RELN and $V L D L R$ (4). Among them, LIS-1 genotype is one of the commonest, and is characterized by a posterior predominance of lissencephaly with thickened cortex. By contrast, the double cortin ( $D C X)$ genotype demonstrates an anterior predominance or has a more diffuse appearance. Furthermore, lissencephaly may be associated with other craniofacial syndromes or callosal and brainstem abnormalities as well as cerebellar dysplasia (5).

The frequency and penetrance of the 19 known 
genetic mutations related to lissencephaly is variable, nonetheless even the rarest ones tend to demonstrate specific phenotypic radiological and clinical appearances. This is in fact the case for $A R X$ gene mutations which are a cause of $\mathrm{X}$-linked lissencephaly with ambiguous genitalia (XLAG). In this rare mutation, the abnormal folding of cortical gyri displays a posterior predominance, with only relative mild cortical thickening. Additional phenotypical features of $A R X$-related lissencephaly are callosal agenesis and small basal ganglia. Clinically, the patients suffer from neonatal epilepsy, which tends to be medically-refractory despite multi-pharmacological treatment. In this form of lissencephaly, clonic convulsions or myoclonus tend to be seen from the first day of life, but neither infantile spasms nor hypsarrhythmia on electroencephalograms have been reported so far (6,11-14). Other symptoms described in the literature include lack of temperature control secondary to hypothalamic dysfunction, chronic diarrhoea secondary to pancreatic malfunction and cardiac abnormalities (15-17); although none of these were demonstrated in our patient. Overall prognosis is dismal, with the average life expectancy being around 18 months and a maximum recorded age of 4 years (18). This is the reason why we felt that this case represented the perfect example to stress the importance of identifying typical radiological features on prenatal US and MRI, highlighting that the finest diagnosis should be sought as soon as possible. The field of prenatal diagnosis based on in utero imaging is evolving at a rapid pace, so that many malformations involving any organ and apparatus (heart, lungs, bladder, genitalia, etc.) can nowadays be picked up at an ultra-early stage (19). Neuroimaging is certainly not lagging behind in this trend setting process.

The $A R X$ gene is part of the homeobox family of proteins and plays an important role in embryonic development, interneuronal migration and forebrain differentiation. Crucially, protein products from the $A R X$ gene also play a role in testicular development (20). Pathogenetic mutations in the $A R X$ gene underlie a wide spectrum of phenotypes comprising many X-linked developmental disorders (21). Depending on the type of genetic mutation, phenotypes range from infantile spasms and mental retardation to lissencephaly and agenesis of the corpus callosum, as seen in XLAG. Hemizygous males are always severely affected, whereas female carriers may be unaffected or have a milder phenotype.

Kitamura et al. were the first to confirm that truncating or missense mutations of the $A R X$ gene are linked to an XLAG phenotype in mice (22). These studies were followed up by screening for, and confirmation of, 'loss-of-function' $A R X$ mutations in families with XLAG phenotypes $(23,24)$. By contrast, other less severe $A R X$-related disorders were shown to be generally associated with hypomorphic and expansion mutations. Cho et al. further defined the pathogenesis of $A R X$-related disorders by demonstrating that $A R X$ mutant cells have loss of DNA binding activity and reduced transcription repression activity when compared to wild type (25). The role of $A R X$ in the generation and tangential migration of GABAergic neurons has been proven in mice models by knockout mutations resulting in the aberrant differentiation and migration of these neurons (26). Hence, the most affected in XLAG are the basal ganglia and ganglionic eminences, as demonstrated in this case. The cortex in an $A R X$ brain is three-layered, as opposed to the usual six, and has been shown to have a significant lack of cortical GABAergic neurons, evidence supporting the role of ARX and the subsequent effects of its mutations (27). As detailed above, beside affecting cortical and neuronal development, $A R X$ plays a crucial role in gonadal development. In mice, $A R X$ expression is strong in fetal testis and $A R X$ knockout mice have smaller testes and a decreased number of Leydig cells (28). The resultant decreased levels of testosterone are the principal cause for the genital ambiguity demonstrated in XLAG patients which can be demonstrated even during fetal US and MRI.

\section{Conclusions}

Although our knowledge of molecular mechanisms underlying brain development and causing congenital brain malformation is far from complete, a correlation between imaging patterns and genetic background can prove relevant in terms of prognostication. Even extremely rare cases, such as the one of $\mathrm{X}$-linked lissencephaly secondary to an $A R X$ mutation described here, can be accurately predicted with a careful assessment of the radiological features of prenatal US and MRI. An imaging diagnosis of XLAG is possible when underdevelopment of the basal ganglia, agenesis of the corpus callosum and ambiguous genitalia are present in addition to lissencephaly. The neonatal refractory epilepsy is a major source of continuous hospital admissions and it is extremely detrimental for both the babies and their families. As such, attempts to identify specific radiological traits of these devastating neurological disorders and anticipate in utero diagnosis is important in order to provide proper counselling and accurate prognosis. 


\section{Acknowledgments}

None.

\section{Footnote}

Conflicts of Interest: The authors have no conflicts of interest to declare.

\section{References}

1. Barkovich AJ, Kuzniecky RI, Jackson GD, Guerrini R, Dobyns WB. A developmental and genetic classification for malformations of cortical development. Neurology 2005;65:1873-87.

2. Ganau L, Prisco L, Ligarotti GKI, Ambu R, Ganau M. Understanding the Pathological Basis of Neurological Diseases Through Diagnostic Platforms Based on Innovations in Biomedical Engineering: New Concepts and Theranostics Perspectives. Medicines (Basel) 2018;5:E22.

3. Di Donato N, Chiari S, Mirzaa GM, Aldinger K, Parrini E, Olds C, Barkovich AJ, Guerrini R, Dobyns WB.Lissencephaly: Expanded imaging and clinical classification. Am J Med Genet A 2017;173:1473-88.

4. Tan AP, Chong WK, Mankad K. Comprehensive genotype-phenotype correlation in lissencephaly. Quant Imaging Med Surg 2018;8:673-93.

5. Tan AP, Mankad K. A unique case of lissencephaly with Crouzon syndrome heterozygous for FGFR2 mutation. Childs Nerv Syst 2018;34:23-5.

6. Mochida GH. Genetics and biology of microcephaly and lissencephaly. Semin Pediatr Neurol 2009;16:120-6.

7. Ganau M, Talenti G, D'Arco F. Teaching NeuroImages: Radiologic features of septo-optic dysplasia plus syndrome. Neurology 2018;91:e2200-1.

8. D'Arco F, Hanagandi P, Ganau M, Krishnan P, Taranath A. Neuroimaging Findings in Lysosomal Disorders: 2018 Update. Top Magn Reson Imaging 2018;27:259-74.

9. Scola E, Ganau M, Robinson R, Cleary M, De Cocker LJL, Mankad K, Triulzi F, D’Arco F. Neuroradiological findings in three cases of pontocerebellar hypoplasia type 9 due to AMPD2 mutation: typical MRI appearances and pearls for differential diagnosis. Quant Imaging Med Surg 2019. In press. doi: 10.21037/qims.2019.08.12.

10. Sherr E. The ARX story (epilepsy, mental retardation, autism, and cerebral malformations): one gene leads to many phenotypes. Curr Opin Pediatr 2003;15:567-71.
11. van Graan LA, Lemieux L, Chaudhary UJ. Methods and utility of EEG-fMRI in epilepsy. Quant Imaging Med Surg 2015;5:300-12.

12. Yoong M. Quantifying the deficit-imaging neurobehavioural impairment in childhood epilepsy. Quant Imaging Med Surg 2015;5:225-37.

13. Winston GP. The role of magnetic resonance imaging techniques in the diagnosis, surgical treatment and biological understanding of epilepsy. Quant Imaging Med Surg 2015;5:186-7.

14. Ngoh A, Bras J, Guerreiro R, Meyer E, McTague A, Dawson E, Mankad K, Gunny R, Clayton P, Mills PB, Thornton R, Lai M, Forsyth R, Kurian MA. RARS2 mutations in a sibship with infantile spasms. Epilepsia 2016;57:e97-102.

15. Dobyns WB, Berry-Kravis E, Havernick NJ, Holden KR, Viskochil D. X-linked lissencephaly with absent corpus callosum and ambiguous genitalia. Am J Med Genet 1999;86:331-7.

16. Ogata T, Matsuo N, Hiraoka N, Hata J. X-linked lissencephaly with ambiguous genitalia: delineation of further case. Am J Med Genet 2000; 94:174-6.

17. Bonneau D, Toutain A, Laquerriere A, Marret S, SaugierVeber P, Barthez MA, Radi S, Biran-Mucignat V, Rodriguez D, Gélot A. X-linked lissencephaly with absent corpus callosum and ambiguous genitalia (XLAG): clinical, magnetic resonance imaging, and neuropathological findings. Ann Neurol 2002;51:340-9.

18. Gupta B, Ramteke P, Paul VK, Kumar T, DAS P. Ambiguous Genitalia Associated with an Extremely Rare Syndrome: A Case Report of XLAG Syndrome and Review of the Literature. Turk Patoloji Derg 2019;35:162-5.

19. Zhang T, Wu S. Prenatal ultrasound diagnosis of 1 case of vesicoureteral reflux. Quant Imaging Med Surg 2016;6:320-2.

20. Miyabayashi K, Katoh-Fukui Y, Ogawa H, Baba T, Shima Y, Sugiyama N, Kitamura K, Morohashi K. Aristaless Related Homeobox Gene, Arx, Is Implicated in Mouse Fetal Leydig Cell Differentiation Possibly through Expressing in the Progenitor Cells. PLoS One 2013;8:e68050.

21. Friocourt G, Poirier K, Rakić S, Parnavelas JG, Chelly J. The role of ARX in cortical development. Eur J Neurosci 2006;23:869-76.

22. Kitamura K, Yanazawa M, Sugiyama N Miura H, IizukaKogo A, Kusaka M, Omichi K, Suzuki R, Kato-Fukui Y, Kamiirisa K, Matsuo M, Kamijo S, Kasahara M, Yoshioka 
H, Ogata T, Fukuda T, Kondo I, Kato M, Dobyns WB, Yokoyama M, Morohashi K. Mutation of ARX causes abnormaldevelopment of forebrain and testes in mice and $\mathrm{X}$-linked lissencephaly with abnormal genitalia in humans. Nat Genet 2002;32:359-69.

23. Uyanik G, Aigner L, Martin P, Gross C, Neumann D, Marschner-Schäfer H, Hehr U, Winkler J. ARX mutations in X-linked lissencephaly with abnormal genitalia. Neurology 2003;61:232-5.

24. Stromme P, Bakke SJ, Dahl A, Gécz J. Brain cysts associated with mutation in the Aristaless related homeobox gene, ARX. J Neurol Neurosurg Psychiatry 2003;74:536-8.

25. Cho G, Nasrallah MP, Lim Y, Golden JA. Distinct DNA

Cite this article as: ffrench-Constant S, Kachramanoglou C, Jones B, Basheer N, Syrmos N, Ganau M, Jan W. Fetal and neonatal MRI features of $A R X$-related lissencephaly presenting with neonatal refractory seizure disorder. Quant Imaging Med Surg 2019;9(11):1767-1772. doi: 10.21037/qims.2019.10.14 binding and transcriptional repression characteristics related to different ARX mutations. Neurogenetics 2012;13:23-9.

26. Kato M, Dobyns WB. X-Linked Lissencephaly With Abnormal Genitalia as a Tangential Migration Disorder Causing Intractable Epilepsy: Proposal for a New Term, "Interneuronopathy." J Child Neurol 2005;20:392-7.

27. Forman MS, Squier W, Dobyns WB, Golden JA. Genotypically defined lissencephalies show distinct pathologies. J Neuropathol Exp Neurol 2005;64:847-57.

28. Yu H, Pask AJ, Hu Y, Shaw G, Renfree MB. ARX/Arx is expressed in germ cells during spermatogenesis in both marsupial and mouse. Reproduction 2014;147:279-89. 